\title{
Transcriptome analysis of Sonneratia caseolaris seedlings under chilling stress
}

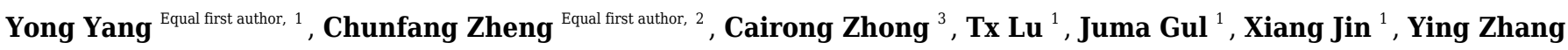 \\ Corresp., 1 , Qiang Liu ${ }^{\text {Corresp. } 1}$ \\ 1 Ministry of Education Key Laboratory for Ecology of Tropical Islands, College of Life Sciences, Hainan Normal University, Haiou, China \\ 2 National and Local Joint Engineering Research Center of Ecological Treatment Technology for Urban Water Pollution, College of Life and Environmental \\ Science, Wenzhou University, Wenzhou, Zhejiang, China \\ 3 Hainan Academy of Forestry, Hainan Mangrove Research Institute, Haikou, Hainan, China \\ Corresponding Authors: Ying Zhang, Qiang Liu \\ Email address: Zhangyingred@yahoo.com, hnsylq@163.com
}

Sonneratia caseolaris is a native mangrove species found in China. It is fast growing and highly adaptable for mangrove afforestation, but suffered great damage by chilling event once introduced to high latitude area. To understand the response mechanisms under chilling stress, physiological and transcriptomic analyses were conducted. The relative electrolyte conductivity, malondialdehyde (MDA) content, soluble sugar content and soluble protein content increased significantly under chilling stress. This indicated that $S$. caseolaris suffered great damage and increased the levels of osmoprotectants in response to the chilling stress. Gene expression comparison analysis of S. caseolaris leaves after $6 \mathrm{~h}$ of chilling stress was performed at the transcriptional scale using RNA-Seq. A total of 168,473 unigenes and 3,706 differentially expressed genes (DEGs) were identified. GO and KEGG enrichment analyses showed that the DEGs were mainly involved in carbohydrate metabolism, antioxidant enzyme, plant hormone signal transduction, and transcription factors (TFs). Twelve genes associated with carbohydrate metabolism, antioxidant enzyme, phytohormones and TFs were selected for qRT-PCR verification, and they indicated that the transcriptome data were reliable. Our work provided a comprehensive review of the chilling response of $S$. caseolaris at both physiological and transcriptomic levels, which will prove useful for further studies on stress-responses in mangrove plants 


\section{Transcriptome Analysis of Sonneratia caseolaris Seedlings}

\section{2 under Chilling Stress}

3 Yong Yang ${ }^{1 \#}$, Chunfang Zheng ${ }^{2 \#}$, Cairong Zhong ${ }^{3}$, Tianxin $\mathrm{Lu}^{1}$, Juma Gul${ }^{1}$, Xiang Jin ${ }^{1}$, Ying

4 Zhang $^{1 *}$, Qiang Liu ${ }^{1 *}$

$5 \quad{ }^{1}$ Ministry of Education Key Laboratory for Ecology of Tropical Islands, College of Life Sciences,

6 Hainan Normal University, Haikou, 571158, China

$7 \quad{ }^{2}$ National and Local Joint Engineering Research Center of Ecological Treatment Technology for

8 Urban Water Pollution, College of Life and Environmental Science, Wenzhou University,

9 Wenzhou, China

$10{ }^{3}$ Hainan Academy of Forestry, Hainan Mangrove Research Institute. Haikou, Hainan, 571100,

11 China

12 \# Co-authors

13 Correspondence:

14 Prof. Ying Zhang and Qiang Liu

15 Zhangyingred@yahoo.com

16 hnsylq@163.com

\section{Abstract}

Sonneratia caseolaris is a mangrove species native to China. It is fast growing and highly adaptable for mangrove afforestation, but injured by cold temperatures when grown at high latitudes. To understand the response mechanisms under chilling stress, we conducted physiological and transcriptomic analyses. The relative electrolyte conductivity, malondialdehyde (MDA) content, soluble sugar content and soluble protein content increased significantly under chilling stress. This indicated that $S$. caseolaris suffered damage and increased the levels of osmoprotectants in response to the chilling stress. We performed gene expression comparison analysis of $S$. caseolaris leaves after $6 \mathrm{~h}$ of chilling stress at the transcriptional scale using RNA- 
27 Seq. A total of 168,473 unigenes and 3,706 differentially expressed genes (DEGs) were identified.

28 GO and KEGG enrichment analyses showed that the DEGs were mainly involved in carbohydrate 29 metabolism, antioxidant enzyme, plant hormone signal transduction, and transcription factors 30 (TFs). Sixteen genes associated with carbohydrate metabolism, antioxidant enzyme,

phytohormones and TFs were selected for qRT-PCR verification, and they indicated that the transcriptome data were reliable. This study reviewed the chilling response of $S$. caseolaris at both physiological and transcriptomic levels, and the results increase our understanding of stressresponses in mangrove plants.

Keywords: Sonneratia caseolaris; chilling stress; RNA-Seq; Differentially expressed genes

\section{Introduction}

The growth, development, and geographical distribution of plants are limited by temperatures in their habitat (Jin et al., 2013). Low temperature stress can be divided into chilling stress $\left(<10^{\circ} \mathrm{C}\right)$ and freezing stress $\left(<0^{\circ} \mathrm{C}\right)$ (Zhou et al., 2011). Plants have evolved a series of response mechanisms to adapt to low-temperature environments. These include regulation of gene expression and physiological and biochemical process changes that enhance cold resistance (Thomshow, 1999; Sung, et al., 2003), These changes have been studied in model plants like Arabidopsis thaliana and some cereal crops ((Buti et al., 2018; Zhang et al., 2004; Roman et al., 2012). Response mechanisms enhancing cold resistance mainly include signaling cascade, modification of the membrane lipid composition, accumulation of osmoprotectants, and increased activity of antioxidant enzymes to scavenge reactive oxygen species (ROS) (Theocharis et al. 2012; Nievola et al. 2017; Nakashima et al., 2009). In addition, phytohormones such as auxin, abscisic acid (ABA), ethylene (ET), jasmonic acid (JA), salicylic acid(SA), gibberellin(GA), cytokinin(CK), and brassinosteroid (BR) and their signal transduction related genes also involved in regulating the gene expression in response to low-temperature stress (Peleg et al., 2011). Exogenous ABA improved the cold tolerance of Brassica napus (He, et al., 2019). Some members of WRKYs and MYBs transcription factors (TFs) regulated gene expression to participate in plant 
54

55

56

cold resistance (An, et al., 2020; Marè, et al., 2004).

Mangroves are halophytic temperature sensitive shrubs or trees that grow in the intertidal areas of tropical and subtropical coasts. They include about 70 species from 20 plant families (Duke, 1992). Mangroves are important in carbon balancing, protecting coastlines and beaches from floods and storms, reducing soil erosion, and providing habitats and shelters for animals. They also provide food, wood, and medical compounds for humans (Duke, 1992; Tomlinson, 1999; Schmitt and Duke, 2015). Large areas of mangroves, however, have been converted to agriculture, aquaculture, and industrial use (Duke et al., 2007; Robertsen and Alongl, 1992; Wang and Wang, 2007). There are approximately 22,684 ha of mangroves in China, which is $44 \%$ of the area existing in the 1950s (survey by State Forestry Administration in 2001). Since 2001, the government of China has focused on mangrove protection and restoration using conservation measures and large-scale afforestation in southeast China. The mangrove area in 2019 had increased to 29,000 ha. Sonneratia caseolaris is a mangrove species that is naturally distributed in the Hainan islands. Because of its rapid growth and adaptability, it was introduced to more northern and colder areas in China, such as Shenzhen and Leizhou in Guangdong Province, Qinzhou and Fangchenggang in Guangxin Province in 1994, where it grows well (Wang et al., 2002; Zan et al., 2003). S. caseolaris suffered substantial chilling injury in 2008, and there was heavy defoliation in all growing areas. All of the trees in Guangxi Province died. There was also significant defoliation of trees in native locations of Wenchang. Young seedlings were the most susceptible growth stage and suffered the great injury (Chen et al., 2017). Mangrove species with greater tolerance to low temperature are needed for mangrove restoration. Understanding the molecular mechanism of $S$. caseolaris tolerance to chilling stress will be of great value in restoration efforts.

Next-generation sequencing (NGS) is an efficient and inexpensive method for collecting transcriptome data. It can be used for species that have not been sequenced. Based on RNA-Seq platforms, genome-scale transcriptome analyses have been used to identify the mechanism of stress response without whole-genome sequence information in different species (He et al., 2015; Kumar et al., 2015). Transcriptome analysis has been used to study adaptive mechanism of 
81

82

83

mangroves, such as Acanthus ilicifolius, Avicennia offcinalis, Bruguiera gymnorhiza, Aegiceras corniculatum and Kandelia obovata (Fang et al., 2016, Krishnamurthy et al., 2017, Su et al., 2019, Yamanaka et al., 2009; Yang et al., 2015a; Yang et al.,2015b). The chilling stress mechanisms of S. caseolaris, however, remains unknown.

To understand the mechanisms of $S$. caseolaris under chilling stress, we first measured the physiological changes in $S$. caseolaris under chilling stress, Then, we used RNA-seq for comparative analyses of $S$. caseolaris leaves between a control group $(0 \mathrm{~h}, \mathrm{CK})$ and a chilling treated group $\left(4^{\circ} \mathrm{C} 6 \mathrm{~h}, \mathrm{CT}\right)$. The reliability of the transcriptome results was verified by real-time quantitative polymerase chain reaction (qRT-PCR). The data improved our understanding of the chilling response mechanism in $S$. caseolaris and identified potential cold tolerance gene targets in this, and other mangrove species.

\section{MATERIALS AND METHODS}

\section{Plant materials and treatments}

We collected ripe fruits of $S$. caseolaris in Hainan Dongzhaigang National Nature Reserve $\left(19^{\circ} 57^{\prime} 23^{\prime \prime} \mathrm{N}, 110^{\circ} 30^{\prime} 10^{\prime \prime} \mathrm{E}\right)$ in China. The fruit was soaked in distilled water for $7 \mathrm{~d}$ and then individually planted in pots with a mud and sand (1:1) mixture as support. Growth chamber conditions were $30 / 28^{\circ} \mathrm{C}$ (day/night) and a $14: 10 \mathrm{~h}$ (L: D) photoperiod, $400 \mu \mathrm{mol} \mathrm{m} \mathrm{m}^{-2} \mathrm{~s}^{-1}$ photon flux density, and $90 \%$ constant humidity. The germinated seeds were cultured in a growth chamber for 5 weeks, at which time the seedlings were about $12 \mathrm{~cm}$ high with 12 leaves. We performed the chilling stress treatment on these seedlings in a growth chamber, by setting the temperature to $4^{\circ} \mathrm{C}$ and leaving the other conditions unchanged. The second leaf from the top of the seedlings were collected as samples from $0 \mathrm{~h}(\mathrm{CK}) 3 \mathrm{~h}, 6 \mathrm{~h}, 12 \mathrm{~h}$ to $24 \mathrm{~h}$ separately, and then frozen in liquid nitrogen and stored at $-80^{\circ} \mathrm{C}$. Each treatment had three biological replicates.

\section{Physiological response assays of chilling-treated seedlings}

We measured relative electrolyte conductivity following Wang et al. (2017). The 
108

109

110

111

112

113

114

115

116

117

118

119

120

121

122

malondialdehyde (MDA) content was measured by the method of Yao et al (2011). The soluble sugar content was measured by the method of Wang et al. (2013). The soluble protein content was measured by using the Bradford method (Bradford et al., 1976). Three biological replicates were measured at each time point.

\section{RNA extraction}

Based on the physiological results, we used the seedlings without chilling as the control group (CK_1, CK_2, CK_3) and seedlings under chilling stress for $6 \mathrm{~h}$ were set as the treatment group (CT_1, CT_2, CT_3) for RNA-seq. Total RNA of leaf samples was extracted with TRIzol reagent (Invitrogen, Carlsbad, CA, USA) according to manufacturer instructions. RNA purity was checked by T6 Spectrophotometer (Puxi, Beijing, China). RNA integrity and concentration were measured by the RNA Nano 6000 Assay Kit of the Agilent Bioanalyzer 2100 system (Agilent Technologies, Santa Clara, CA, USA).

\section{cDNA library construction and transcriptome sequencing}

A $3 \mu \mathrm{g}$ amount of total RNA of each sample was enriched using magnetic beads with Oligo (dT) and then fragmented into short fragments $\sim 200$ bp by an interrupting reagent. The first strand cDNA was synthesized by a random hexamer primer, and the second strand of cDNAs was synthesized using the buffer, dNTPs, DNA polymerase I, and RNase H. After the double-stranded cDNA was generated and processed with end-repair, A-tailed, and adapters ligation, we constructed a cDNA library by PCR amplification. The cDNA library was then sequenced using the BGISEQ-500 platform with paired-end reads of $100 \mathrm{bp}$, by the Beijing Genomic Institution (www.genomics.org.cn, BGI, Shenzhen, China). All raw reads data from this study were submitted to the National Center for Biotechnology Information (NCBI) Sequence Read Archive database under the accession number PRJNA668053.

\section{Transcripts assembly and functional gene annotation}


135

136

137

138

139

140

141

142

143

144

145

146

147

148

149

150

151

152

153

\section{4}

155

156

157

158

159

160

161

The raw data were filtered with SOAPnuke (v1.5.2) (Li et al., 2008). We discarded the low quality reads such as those with adapter sequences, ambiguous bases ' $N$ ' is more than $5 \%$, with more than $20 \% \mathrm{Q}<10$ bases. The remaining clean data were used for de novo assembly with the Trinity program (v2.0.6) (Grabherr et al., 2011) and then the unigene sequences were aligned with the following databases: NR, NT, SwissProt, KEGG, KOG, Pfam and GO by BLAST software (version 2.2.26).

\section{Differential expression analyses}

The expression level of each transcript was measured by RSEM (v1.2.12), and the expression level of a single gene was expressed as the value of FPKM (fragments per kilobase of transcript per million mapped reads) method (Li et al., 2011). For the sake of determining the differentially expressed genes (DEGs), we performed differential expression analysis by the DESeq2 (Anders and Huber, 2010). A P-value $\leqslant 0.05$ and an expression level $\mid \log 2$ (ratio) $\mid>2$ were regarded as significant differential expression. Gene ontology (GO) enrichment analysis of DEGs was conducted using the GOseq $\mathrm{R}$ package, GO terms with $p<0.05$ were regarded as significantly enriched in DEGs (Young et al., 2010). We analyzed the KEGG pathway functional enrichment of DEGs using the R package. Significant enrichment was defined as when the FDR terms were < 0.001 .

\section{Quantitative real-time PCR analysis}

We selected 12 DEGs to verify the reliability of transcriptome sequencing through qRTPCR. The specific primers of qRT-PCR were designed by Primer3 software (http://primer3.ut.ee/) and are listed in Table S1. The qRT-PCR analyses were conducted using a LightCycler 480 RTPCR system (Roche Applied Science, Mannheim, Germany) under the following conditions: $95^{\circ} \mathrm{C}$ for $3 \mathrm{~min}, 40$ cycles of $95^{\circ} \mathrm{C}$ for $15 \mathrm{~s}, 56^{\circ} \mathrm{C}$ for $30 \mathrm{~s}$, and $72^{\circ} \mathrm{C}$ for $20 \mathrm{~s}$. Three replicates of each cDNA sample were performed for qRT-PCR analysis. We calculated the relative expression of each gene by the $2^{-\mathrm{DDCt}}$ method (Livak et al., 2001) and used the actins gene of $S$. caseolaris as a 
162

163

164

165

166

167

168

169

170

171

172

173

174

175

176

177

178

179

180

181

182

183

184

185

186

187

188

reference.

\section{RESULTS}

\section{Physiological responses of $S$. apetala seedlings under chilling stress}

After $3 \mathrm{~h}$ exposure to $4^{\circ} \mathrm{C}$, the leaves at the top of $S$. caseolaris seedlings began to show a slight curling, and after $6 \mathrm{~h}$, the leaves in the top showed evident curling. After $12 \mathrm{~h}$ of chilling stress treatment, part of leaves had softened and exhibited loss of strength. After $24 \mathrm{~h}$ of $4^{\circ} \mathrm{C}$ chilling stress, most of leaves had withered (Figure 1). Electrolyte leakage, MDA content, soluble sugar content and soluble protein content increased significantly (Figure 2). The electrolyte leakage increased from $6.54 \pm 0.46 \%(0 \mathrm{~h})$ to $28.56 \pm 5.32 \%(24 \mathrm{~h})$; the MDA content increased from $2.15 \pm 0.79 \mu \mathrm{mol} / \mathrm{g}(0 \mathrm{~h})$ to $14.01 \pm 1.58 \mu \mathrm{mol} / \mathrm{g}(24 \mathrm{~h})$; the soluble sugar contents increased from $2.79 \pm 0.76 \mu \mathrm{mol} / \mathrm{g}(0 \mathrm{~h})$ to $7.87 \pm 1.67 \mu \mathrm{mol} / \mathrm{g}(24 \mathrm{~h})$; and the soluble protein content increased from $6.00 \pm 0.84 \mu \mathrm{mol} / \mathrm{g}(0 \mathrm{~h})$ to $33.83 \pm 2.27 \mu \mathrm{mol} / \mathrm{g}(24 \mathrm{~h})$. All of these parameters showed a linear increase. When exposed to chilling stress for $6 \mathrm{~h}$, these parameters increased $118.68 \%, 299.98 \%, 160.67 \%$ and $56.15 \%$ compared with the control group. On the basis of these

results, we selected the leaf samples exposed to $0 \mathrm{~h}$ and $6 \mathrm{~h}$ of chilling stress for RNA-seq to investigate the changes in genome-wide gene expression mechanism under chilling stress. The 0 $\mathrm{h}$ time the control $(\mathrm{CK})$ and $6 \mathrm{~h}$ was regarded as the treatment group $(\mathrm{CT})$, with three biological replicates.

\section{Sequencing and de novo assembly of transcriptome}

In total, we obtained $39.33 \mathrm{~Gb}$ clean bases from 6 cDNA libraries, and we obtained a total of 262.21 M clean reads from 280.46 M raw reads (Table S2). The clean reads were de novo assembled by Trinity software and they yielded 168,473 unigenes. All unigenes were longer than $200 \mathrm{bp}$ and ranged from 297 to $16,287 \mathrm{bp}$. The 200-300 bp unigenes accounted for the largest proportion $(13,159,12.26 \%)$ (Figure S1A). The mean unigene length was 1,762 bp. The N50 and N90 lengths were 2,849 bp and 937 bp respectively, and the GC content was $43.94 \%$. 
Gene annotation and functional classification

191

192

193

194

195

196

197

198

199

200

201

202

203

204

205

206

207

208

209

210

211

212

213

214

215

To predict the putative function of the assembled unigenes, we used BLAST to compare seven databases including NR, NT, SwissProt, KEGG, KOG, Pfam and GO. The E-value cut-off was 105. A total of $125,360(74.41 \%)$ unigenes were predicted to be homologous with known genes from the databases listed earlier. Among them, 116,619 (69.22\%), 85,761 (50.90\%), 90,660 (53.81\%), 94,737 (56.23\%), 100,382 (59.58\%), 96,869 (57.50\%) and 92,876 (55.13\%) unigenes were found in the seven databases. A total of 48,858 (29.00\%) were found in all seven databases (Table S3). The NR database had the highest proportion of annotations, with $69.22 \%$ unigenes being annotated. In the NR database, the unigene sequences exhibited the most similar BLASTx matches to gene sequences from Punica granatum (84,763, 72.69\%), followed by Eucalyptus grandis (4,627, 3.97\%) amd Quercus suber (1125, 0.96\%) (Figure S1B).

We classified the functions of the $S$. caseolaris unigenes by GO analysis and categorized 92,876 of the unigenes into 44 functional groups. These groups were classified into the following three major GO categories: 18 functional groups in "biological processes", 12 functional groups in "cell component", and 14 functional groups in "molecular function". The dominant subcategories of the classified genes included "metabolic process $(9,916)$ ", "cellular process $(22,187)$ ", and "biological regulation $(10,062)$ " in the "biological processes" category; "membrane part $(29,068)$ ", "cell $(23,014)$ ", and "organelle part $(9,821)$ "in the "cell component" category; "binding"(46,922), "catalytic activity $(44,729)$ "and "transporter activity $(5,902)$ "in the "molecular function" category (Figure S1C). To analyze the intracellular metabolic pathways and biological functions in S. caseolaris, we conducted a KEGG analysis using the KEGG pathway tool. Genes were annotated to five categories. 1 functional group in "Cellular Processes", 2 functional groups in "Environmental Information Processing", 3 functional groups in "Genetic Information Processing", 11 functional groups in "Metabolism", and 1 functional group in "Organismal Systems" (Figure S1D). 
216

217

218

219

220

221

222

223

224

225

226

227

228

229

230

231

232

233

234

235

236

237

238

239

240

241

242

\section{GO term enrichment analysis of DEGs}

We identified a total of 3,706 DEGs, including 2,501 that were up-regulated and 1,205 that were down-regulated under the chilling stress (Figure S2). The biological function information for the DEGs was analyzed by GO enrichment. A total of 2,902 DEGs were annotated in 1,411 terms and a total of $125 \mathrm{GO}$ terms were identified. The most enriched GO categories among these DEGs were "nucleus", "DNA binding", "metal ion binding", "DNA-binding transcription factor activity", and "regulation of transcription, DNA-templated", with 366, 239, 204, 128, and 125 DEGs respectively (Figure $3 \mathrm{~A})$.

\section{Pathway enrichment analysis of DEGs}

To characterize the active biological pathways of the DEGs in S. caseolaris under chilling stress, we classified the DEGs in KEGG biological pathways and conducted enrichment analysis. There were 2,557 DEGs annotated in 125 pathways. Among them, a total of nine KEGG pathways were significantly enriched with a $\mathrm{P}$-value $\leqslant 0.05$. The three most highly represented pathways were "Plant hormone signal transduction (ko04075)", "Plant-pathogen interaction (ko04626)", and "Glycerophospholipid metabolism (ko00564)", with 115, 88 and 41 DEGs respectively (Figure 3B). The largest number of DEGs included "plant hormone signal transduction", indicating that plant hormones play an important role in response to chilling stress in S. caseolaris. The second largest number of DEGs included "Plant-pathogen interaction", which suggested that low temperature exposed plants are more vulnerable to be pathogen infection. The "Glycerophospholipid metabolism" category had the third largest number of DEGs, suggesting that fatty acid metabolism responded positively to low temperature. A considerable number of biological reactions were altered in S. caseolaris in response to chilling stress.

\section{DEGs associated with chilling stress}

Carbohydrate metabolism related DEGs

Carbohydrates played an important role in plant response to low temperatures. In GO 
243 enrichment analysis, 12 DEGs were enriched in "starch binding (GO:2001070)" and all were up-

244 regulated. Many DEGs that were involved in starch, fructose, sucrose, glucose, and trehalose were 245 up-regulated in chilling stress (Figure 4A). Four genes (CL1250.Contig10_All, 246 CL13708.Contig9_All, CL3523.Contig11_All, and CL5529.Contig9_All) were involved in 247 trehalose biosynthetic process, two sucrose synthase genes (CL14150.Contig25_All and 248 CL2626.Contig4_All), and one sucrose-phosphate synthase gene (CL2626.Contig4_All) were 249 involved in the sucrose process. Many DEGs were involved in "Pentose phosphate pathway 250 (ko00030)", "Fructose and mannose metabolism (ko00051)", "Galactose metabolism (ko00052)", 251 "Pentose and glucoronate interconversions (ko00040)", and "Starch and sucrose metabolism 252 (ko00500)" respectively, and most of these were up-regulated.

253

\section{Phytohormone related DEGs}

KEGG analysis of DEGs in $S$. caseolaris showed that hormone signal transduction was 256 significantly influenced by chilling stress (Figure 3). There were 115 DEGs enriched in "plant

257

258

259

260

261

262

263

264

265

266

267

268

269 hormone signal transduction" and most of them were up-regulated (Figure 5). Especially in auxin signal transduction, ABA signal transduction, ET signal transduction and JA signal transduction.

In this GO analysis of DEGs, 41 DEGs enriched in the "auxin-activated signaling pathway (GO:0009734)" term. Among them, AUX1 (Unigene13181_All) is a key gene that encodes an auxin receptor, and down-regulated 2.50 fold. In the ABA signal pathway, PLY and PP2C are key enzymes controlled by the ABA signaling pathway. In this study, the genes encoding these two enzymes (CL1229.Contig3_All, Unigene14664_All, and CL5508.Contig1_All) were all upregulated. Additionally, seven DEGs were enriched in the "abscisic acid-activated signaling pathway (GO:0009738)" term. In the ET signal pathway, we found that the one gene (CL2232.Contig4_All) encoding ETR down-regulated 6.81 fold. |In the Ja signal pathway, cetylCoA acyltransferase 1 is a key enzyme for synthesis of JA-CoA. In this study, the genes (CL10456.Contig6_All) encoding this enzyme were up-regulated by 3.93-fold. 
270

271

272

273

274

275

276

277

278

279

280

281

282

283

284

285

286

287

288

289

290

291

292

293

294

295

296

\section{ROS related DEGs}

We found DEGs related to catalase, glutathione peroxidase, peroxidase, and superoxide dismutase were involved in chilling stress (Figure 4B). Two genes encode superoxide dismutase (CL10965.Contig3_All and CL355.Contig5_All). 3 genes encode catalase (Unigene30041_All, Unigene30063_All and Unigene30085_All), and 10 genes encode peroxidase (CL1068.Contig11_All, CL1068.Contig6_All, CL1068.Contig7_All, CL11425.Contig1_All, CL13638.Contig5_All, CL2936.Contig3_All, CL3639.Contig5_All, CL3639.Contig6_All, CL4125.Contig8_All, and Unigene3189_All). These genes were all up-regulated, indicating that they may have played a positive role in activating antioxidant enzymes in $S$. caseolaris exposed to low temperatures.

\section{Transcription factors}

TFs play an important role in regulating gene expression that participates in plant stress regulatory processes, such as chilling stress-related processes. In this study, we classified a total of 232 TFs into 41 families and showed differential expression in chilling treated seedlings. A total of $161(69.40 \%)$ were up-regulated. The five most abundant TF families were AP2-ERF, MYB, C3H, WRKY, and ARF with 35 (15.09\%), 29 (12.50\%) 21 (9.05\%), 21 (9.05\%), and 15 (6.47\%) respectively (Figure 4C).

\section{Validation of transcriptome data by RT-qPCR analyses}

To validate the RNA-Seq results, we selected a total of 16 candidate genes for qRT-PCR analyses (Figure 6). Based on enrichment analyses, all of these genes were involved in the chilling response. They represented different functional categories or pathways, such as sugar metabolism, antioxidant enzyme, phytohormones and TFs. The results indicated that the transcriptome results were reliable.

\section{DISCUSSION}


With its rapid growth adaptability, $S$. caseolaris is a good candidate species for mangrove afforestation in China. Low temperature, however, have limited its distribution in high latitude areas. Understanding the physiological and molecular mechanisms of chilling resistance can aid in breeding cold tolerant varieties of $S$. caseolaris. We performed physiological and transcriptomic analyses of leaves under $4^{\circ} \mathrm{C}$ chilling stress, and then analyzed the DEGs involved in the antioxidant defense system, carbohydrate metabolism, plant hormone signals, and TFs.

\section{Membrane injury of $S$. caseolaris seedlings caused by chilling stress}

Membrane lipids are the first place that plants perceive and respond to abiotic stress signals such as low temperature. Lipids are involved in biological process, such as signal transduction, energy conversion, and metabolic regulation (Xie et al., 2018). Damaged membrane lipids increase electrolyte leakage, and a high electrolyte leakage rate reflects serious damage caused by chilling stress. Membrane permeability is an important physiological index of plant resistance to stress. MDA is the final degradation product of lipid peroxidation, and the MDA level reflects the damage of membrane lipid peroxidation and the stress tolerance of plant cells (Mutlu et al., 2013; Wise and Naylor, 1987). Physiological analysis showed that the relative electrolyte conductivity and the MDA level both increased significantly after chilling stress. Membrane lipid peroxidation likely occurred and membrane lipids were damaged. Similar results were found in Magnolia wufengensis (Deng et al., 2019). Serious member lipid injury can result in seedling death. This might explain why most seedlings died when exposed to extreme low temperatures (Chen et al., 2017). We found that DEGs were enriched in "Glycerophospholipid metabolism (ko00062)" and "Fatty acid elongation (ko00564)". The genes responded to the increased level of unsaturated fatty acids and membrane fluidity in the cells of $S$. caseolaris seedlings under chilling stress, which may be a mechanism of cellular self-repair.

\section{Carbohydrate metabolism-related DEGs}

When exposed to low temperatures, plants usually break down starch and increase the content of carbohydrates to maintain stability of cell membrane structure, this could increase the low 
324

325

326

327

328

329

330

331

332

333

334

335

336

337

338

339

340

341

342

343

344

345

346

347

348

349

350

temperature tolerance of plant cells (Guy et al., 2008). In GO enrichment analysis, 12 DEGs were enriched in "starch binding (GO:2001070)" (Figure 3B). This could result in the conversion of starch into soluble sugar under chilling stress. Physiological experiments confirmed that the soluble sugars content of $S$. caseolaris increased after chilling stress. Increased levels of sucrose, raffinose, glucose, and fructose are involved in the low-temperature resistance of other plants (Anchordoguy et al., 1987; Ma et al., 2009). The RNA-seq data showed that many DEGs that are involved in starch, fructose, sucrose, glucose, and trehalose were up-regulated in chilling stress treatment. These data were consistent with previous studies (Wang et al., 2018, Deng, et al., 2019; Yang et al., 2019). Plants can accumulate trehalose for oxidative detoxification to counteract abiotic stresses (Lai et al., 2017). In the DEGs, four genes were involved in the trehalose biosynthetic process and all of them were up-regulated, which is similar to the report of Deng et al. (2019). Sucrose synthase and sucrose phosphate synthase play important roles in sucrose metabolism and biosynthesis respectively (Winter and Huber, 2000). We found that two sucrose synthase genes and one sucrose-phosphate synthase gene were up-regulated. These genes may have been involved in the response to chilling stress. A similar result was found by Yang et al. (2019). Carbohydrate also regulate expression of jasmonate, ABA and COR genes (Rutten and Santarius, 1992; Welling and Palva, 2006). We found that many DEGs were involved in carbohydrate metabolism, which indicated that carbohydrates play an important role in $S$. caseolaris response to chilling stress.

\section{Antioxidant defense system}

Under environment stress, ROS such as superoxide, hydroxyl radicals and hydrogen peroxide can accumulate in plant cells and cause oxidative damage (Elsheery et al., 2008; Suzuki and Mittler, 2006). To scavenge ROS, antioxidant systems such as superoxide dismutase (SOD), catalase (CAT), peroxidase (POD), and ascorbate peroxidase (APX) are activated in response to plant stress (Mittler, 2002). SOD is the first antioxidant enzyme that could convert $\mathrm{O}^{2-}$ to hydrogen peroxide $\left(\mathrm{H}_{2} \mathrm{O}_{2}\right)$, and then POD and CAT could catalyze $\mathrm{H}_{2} \mathrm{O}_{2}$ and convert it to $\mathrm{H}_{2} \mathrm{O}$. We found 
351

352

353

354

355

356

357

358

359

360

361

362

363

364

365

366

367

368

369

370

371

372

373

374

375

376

377

DEGs related to CAT, glutathione peroxidase, POD, and SOD were up-regulated, indicating that they may have played a key role in activating antioxidant enzymes in S. caseolaris exposed to low temperatures. ROS are also signal molecules that can induce gene expression and protein synthesis to increase stress tolerance in plants (Jaspers and Kangasjärvi, et al., 2010). ROS also is active the mitogen-activated protein kinase (MAPK) cascade pathway, which regulates low-temperature response genes involved in TFs and some hormones. (Pitzschke, et al., 2009; Xie, et al., 2009). We found 15 DEGs enriched in "MAP kinase activity" and most of them were un-regulated, which indicated that MAPK signal transduction pathway also played an important role in chilling stress responses.

These results indicated that many antioxidant genes are activated, and these would not only increase the activity of antioxidant enzymes to scavenge with ROS, but also active a sequence of signal to response chilling stress.

\section{Phytohormone signal network responses to chilling stress}

Phytohormones are the secondary signals in plant cells that play a significant role in adaptation to environmental stress (Peleg et al., 2011). They can activate a sequence of signal events and eventually induce the genes that directly respond to stress (Bari and Jones, 2009; Hakeem et al., 2014). We found four key response hormone signal transduction pathways (auxin, ABA, EN, and JA) that were significantly influenced by chilling stress. Auxin is a plant growthpromoting hormone (Nemhauser et al., 2006). In this study, 41 DEGs were enriched in the "auxinactivated signaling pathway (GO:0009734)" term. Down-regulation of the $A U X 1$ gene may reduce plant growth in response to chilling stress. The ABA signaling pathway is important in regulating abiotic stress responses in plants (Danquah, et al., 2014). It can regulate stomatal closure, reduce water loss and maintain cell growth (Peleg \& Blumwald, 2011). PLY and PP2C are key genes controlled by the ABA signaling pathway. In present study, the genes were up-regulated in response to chilling stress. This could activate high expression of PP2C and promote stomatal closure and decrease transpiration to reduce water loss. Similar results have been found on 
378

379

380

381

382

383

384

385

386

387

388

389

390

391

392

393

394

395

396

397

398

399

400

401

402

403

404

Arabidopsis thaliana (Tähtiharju and Palva, 2001) and Oryza sativa L (Guan et al., 2019). Additionally, the DEGs were also enriched in the "abscisic acid-activated signaling pathway (GO:0009738)" term, which further confirmed that ABA-dependent signaling is involved in the low temperature response of $S$. caseolaris. Genes related to ET biosynthesis often down-regulated expressed under low temperature treatment (Chu and Lee, 1989). In this study, the key gene encoding ETR was down-regulated, which was consistent with previous reports (Yang et al., 2018). JA plays a significant role in plants responding to abiotic and biotic stress (Wasternack and Song, 2017; Wasternack and Strnad, 2018). The up-regulated key genes may promote the synthesis of JA-CoA and promote the synthesis of JA. Exogenous methyl salicylic acid (MeSA) or methyl jasmonate (MeJA) could induce the transcription of pathogenesis-related genes, and increase chilling tolerance and pathogen resistance (Ding, et al., 2002). This may explain why many DEGs were enriched in "Plant-pathogen interaction". Similar results have been found in K. obovate, $M$. wufengensis, and Camellia sinensis under chilling stress (Deng, et al., 2019; Li et al., 2019; Su et al., 2019). However, how those plant hormones mediated signaling participates in chilling stress responses in S. caseolaris still need to be further study.

\section{TFs responding to chilling stress}

TFs play important roles in plant growth and stress tolerance (Lee et al., 2005). When a plant experiences the chilling stress, a series of signal transduction pathways could activate TFs. The activated TFs will activate the expressions of a cascade of downstream resistance-related genes to enhance the cold tolerance by special binding (Kasuga et al., 1999). Many TF families such as DREB (Ahmed et al., 2017, Chen et al. 2012), MYB (Zhao et al., 2012, Agarwal et al., 2006; Chen et al., 2006), and WRKY (Zou et al., 2010) are related to plants resistance to low temperature stress. We identified $232 \mathrm{TFs}$ that were classified into 41 families. AP2-ERF, MYB, C3H, WRKY, and ARF were five major TF families identified as DEGs, suggest that they played a crucial role in response to chilling stress. AP2-ERF genes belong to a plant-specific TF family involved in regulating stress responses (Mizoi et al., 2012). The AP2-ERF superfamily consists of the ERF, 
405

406

407

408

409

410

411

412

413

414

415

416

417

418

419

420

421

422

423

424

425

426

427

428

429

430

431

RAV, AP2, and DREB families. Overexpression of $A P 2 T F, J_{c} D R E B$, and $B p D R E B 2$ increased cold tolerance of Arabidopsis (Tang et al., 2011; Sun et al., 2014). Previous studies verified that AP2-ERFs involved in a lot of plant hormone mediated abiotic stress responses, such as ABA, ET, GA, CTK, and BR (Colebrook et al., 2014; Kazan et al., 2015; Tao et al., 2015; Nolan et al.,2017; Sah et al., 2016). MYB are involved in chilling stress and regulation of ABA-responsive genes, and constitute with ABA-dependent, induced and mediated types. Which plays an important role in the upstream stage of low temperature transduction (Gyoungju et al., 2016). AtMYB52, AtMYB70, and AtMYB82 were ABA-dependent genes in responding abiotic stresses of Arabidopsis (Park et al, 2011); TaMYB1, TaMYB2, TaMYB3R1 were ABA-induced genes in responding abiotic stresses of wheat (Cai et al., 2011; Tong et al., 2006); AtMYB2, AtMYB41 were ABA-mediated types that promote the accumulation of ABA in responding abiotic stresses (Abe et al., 2003; Lippold et al., 2009). The WRKY genes can respond strongly and rapidly to abiotic stresses (Chen et al., 2012). The WRKY46 gene enhanced the low temperature tolerance of transgenic cucumber by activating a series of cold-stress responsive genes in an ABA-dependent manner (Zhang et al., 2016). MaWRKY25 can be induced by low temperature or MeJA, which could increase the low temperature tolerance of banana. It could also active the $M a L O X 2, M a A O S 3, M a O P R 3$ genes to promote the synthesis of JA by special binding. Which could reduce the damage of banana fruit by low temperature (Ye, et al., 2016). Other TFs, such as the HSF, bZIP, and GRAS families, are induced by chilling stress, and members of these families can affect the cold resistance of plants (Chinnusamy et al., 2010). These results indicated that many TFs were involved in the seedlings of $S$. caseolaris in response to chilling stress through different pathways. Besides, the both unregulated TFs and phytohormones maybe have some connection, and the regulatory network need further study.

29 Conclusions

We analyzed at the morphological, physiological and transcriptome level of $S$. caseolaris response to chilling stress. Chilling stress of $S$. caseolaris likely involves damage to the cell 
432 membranes. This was supported by a significant increase in the relative electrolyte conductivity 433 and MDA contents. Up regulating genes in chilling stressed S. caseolaris were involved in plant 434 hormone signal transduction, TFs, carbohydrate metabolism, and antioxidant enzymes. These 435 genes might be involved in the significant increase of soluble protein content and soluble sugar 436 content in response to the chilling stress (Figure 7). These data revealed the manner in which $S$. 437 caseolaris responds to chilling stress, and provided insight for further research on the 438 environmental adaptations of mangrove species.

439

440 Figure 1 Phenotypic changes of $S$. caseolaris under chilling stress $\left(4^{\circ} \mathrm{C}\right)$.

441 Figure 2 Physiological change of $S$. caseolaris in chilling stress. Error bar indicates \pm SD of three 442 replicates.

443 Figure 3 The top $20 \mathrm{GO}$ and KEGG enrichment scatter diagram depicting the differential 444 expression of genes. A: the top $20 \mathrm{GO}$ enrichment B: KEGG enrichment.

445 Figure 4 Heat map of relative expression levels of DEGs involved in main transcription factors, 446 sugar metabolism and the antioxidant defense system. A: The main sugar metabolism-related 447 genes. B: The main antioxidant-related genes. C: The main transcription factors.

448 Figure 5 Plant hormone signal transduction and the relative heat map. A Plant hormone signal 449 transduction. B Heat map of DEGs involved with auxin, ABA, ET and JA.

450 Figure 6 Expression of $S$. caseolaris genes in response to chilling stress for $0 \mathrm{~h}(\mathrm{CK})$ and $6 \mathrm{~h}(\mathrm{CT})$ 451 as determined by qRT-PCR (blue) and RNA-seq (red).

452 Figure 7 Hypothetical model of the events occurring in the S. caseolaris leaves under chilling 453 stress.

455 Table S1 List of primers used in this study

456 Table S2 Summary of sequence analysis

457 Table S3 Number of annotated unigenes 
459 Figure S1 Characteristics of unigenes. A: Distribution of unigene lengths in Sonneratia caseolaris. 460 B: Main species distribution of $S$. caseolaris unigenes. C: Pathway annotation of unigenes based 461 on KEGG categorization D: Functional annotation of unigenes based on Gene Ontology (GO) 462 categorization.

463 Figure S2 Volcano diagram showing the differential expression of genes. Blue represents down464 regulated, red indicates up-regulated

\section{REFERENCES}

Abe H, Urao T, Ito T, Seki M, Shinozaki K, Yamaguchi-Shinozaki K. 2003. Arabidopsis AtMYC2 (bHLH) and AtMYB2 (MYB) function as transcriptional activators in abscisic acid signaling. The Plant cell 15(1): 63-78 DOI 10.1105/tpc.006130.

Agarwal M, Hao Y, Kapoor A, Dong CH, Fujii H, Zheng X, Zhu JK. 2006. A R2R3 type MYB transcription factor is involved in the cold regulation of $C B F$ genes and in acquired freezing tolerance. The Journal of biological chemistry 281(49): 37636-37645 DOI 10.1074/jbc.M605895200.

Ahmed MM, Shen C, Khan AQ, Wahid MA, Shaban M, Lin Z. 2017. A comparative genomics approach revealed evolutionary dynamics of microsatellite imperfection and conservation in genus Gossypium. Hereditas 154: 12 DOI 10.1186/s41065-017-0034-4.

An JP, Wang XF, Zhang XW, Xu HF, Bi SQ, You CX, \& Hao YJ. 2020. An apple MYB transcription factor regulates cold tolerance and anthocyanin accumulation and undergoes MIEL1-mediated degradation. Plant biotechnology journal 18(2): 337-353. DOI 10.1111/pbi.13201.

Anchordoguy TJ, Rudolph AS, Carpenter JF, Crowe JH. 1987. Modes of interaction of cryoprotectants with membrane phospholipids during freezing. Cryobiology 24(4): 324-331. DOI 10.1016/0011-2240(87)90036-8.

Anders S and Huber W. 2010. Differential expression analysis for sequence count data. Genome biology, 11(10): R106 DOI 10.1186/gb-2010-11-10-r106. 
486

487

488

489

490

491

492

493

494

495

496

497

498

499

500

501

502

503

504

505

506

507

508

509

510

511

512

Bari R and Jones J. 2009. Role of plant hormones in plant defence responses. Plant molecular biology 69(4): 473-488 DOI 10.1007/s11103-008-9435-0.

Bradford MM. 1976. A rapid and sensitive method for the quantitation of microgram quantities of protein utilizing the principle of protein-dye binding. Analytical biochemistry 72: 248-254 DOI 10.1006/abio.1976.9999.

Buti M, Pasquariello M, Ronga D, Milc JA, Pecchioni N, Ho VT, Pucciariello C, Perata P, Francia E. 2018. Transcriptome profiling of short-term response to chilling stress in tolerant and sensitive Oryza sativa ssp. Japonica seedlings. Functional \& integrative genomics 18(6): 627644. DOI 10.1007/s10142-018-0615-y

Chen LG, Song Y, Li SJ, Zhang LP, Zou CS, Yu DQ. 2012. The role of WRKY transcription factors in plant abiotic stresses. Biochimica et biophysica acta 1819(2): 120-128. DOI 10.1016/j.bbagrm.2011.09.002.

Chen LZ, Wang WQ, Li QQ, Zhang YH, Yang S, Osland MJ, Huang J, Peng CJ. 2017. Mangrove species' responses to winter air temperature extremes in China. Ecosphere 8(6): e01865 DOI $10.1002 /$ ecs 2.1865 .

Chen YH, Yang XY, He K, Liu MH, Li JG, Gao ZF, Lin ZQ, Zhang YF, Wang XX, Qiu XM, Shen YP, Zhang L, Deng XH, Luo JC, Deng XW, Chen ZL, Gu HY, Qu LJ. 2006. The MYB transcription factor superfamily of Arabidopsis: expression analysis and phylogenetic comparison with the rice MYB family. Plant molecular biology 60(1): 107-124. DOI 10.1007/s11103-005-2910-y.

Chikako K and Ryozo I. 2009. Molecular basis of disease resistance acquired through cold acclimation in overwintering plants. Journal of plant biology 52:19-26. DOI 10.1007/s12374008-9006-6

Chinnusamy V, Zhu JK, Sunkar R. 2010. Gene regulation during cold stress acclimation in plants. Methods in molecular biology 639: 39-55 DOI 10.1007/978-1-60761-702-0_3.

Chu $\mathrm{C}$ and Lee TM. 1989. The relationship between ethylene biosynthesis and chilling tolerance in seedlings of rice (Oryza sativa). Bot Bull Acad Sin 130:263-273. 
513 Colebrook EH, Thomas SG, Phillips AL, Hedden P. 2014. The role of gibberellin signalling in 514 plant responses to abiotic stress. The Journal of experimental biology, 217(1): 67-75 DOI $515 \quad 10.1242 /$ jeb.089938.

516 Danquah A, de Zelicourt A, Colcombet J, \& Hirt H. 2014. The role of ABA and MAPK signaling 517 pathways in plant abiotic stress responses. Biotechnology advances, 32(1): 40-52. DOI $518 \quad$ 10.1016/j.biotechadv.2013.09.006.

519 Deng S, Ma J, Zhang L, Chen F, Sang Z, Jia Z, Ma L. 2019. De novo transcriptome sequencing 520 and gene expression profiling of Magnolia wufengensis in response to cold stress. BMC plant 
541

542

543

544

545

546

547

548

549

550

551

552

553

554

555

556

557

558

559

560

561

562

563

564

565

566

Guan SG, Xu Q, Ma DR, Zhang WZ, Xu ZJ, Zhang MG, Guo ZF. 2019. Transcriptomics profiling in response to cold stress in cultivated rice and weedy rice. Gene 685:96-105 DOI 10.1016/j.gene.2018.10.066.

Guy C, Kaplan F, Kopka J, Selbig J, and Hincha DK. 2008. Metabolomics of temperature stress. Physiologia plantarum 132(2): 220-235 DOI 10.1111/j.1399-3054.2007.00999.x.

Gyoungju N, Moonsub L, Do-Soon K, Lane RA, Thomas V and Lee DK. 2016. Transcriptome analysis of Spartina pectinatain response to freezing stress. PloS one 11(3): e0152294 DOI 10.1371/journal.pone.0152294.

Hakeem KR, Rehman RU, Tahir I. 2014. Plant signaling: understanding the molecular crosstalk \| signaling in response to cold stress 10:193-226 DOI 10.1007/978-81-322-1542-4_10.

He W, Zhuang H, Fu Y, Guo L, Guo B, Guo L, Zhang X, Wei Y. 2015. De novo Transcriptome Assembly of a Chinese Locoweed (Oxytropis ochrocephala) Species Provides Insights into Genes Associated with Drought, Salinity, and Cold Tolerance. Frontiers in plant science 2(6): 1086 DOI 10.3389/fpls.2015.01086.

Jaspers P and Kangasjärvi J 2010. Reactive oxygen species in abiotic stress signaling. Physiologia plantarum 138(4): 405-413 DOI 10.1111/j.1399-3054.2009.01321.x

Jin J and Kim J. 2013. Cold stress signaling networks in Arabidopsis. Journal of Plant Biology 56(2): 69-76 DOI 10.1007/s12374-013-0903-y.

Kasuga M, Liu Q, Miura S, Yamaguchi-Shinozaki K, Shinozaki K. 1999. Improving plant drought, salt, and freezing tolerance by gene transfer of a single stress-inducible transcription factor. Nature biotechnology 17(3): 287-291 DOI 10.1038/7036.

Kazan K. 2015. Diverse roles of jasmonates and ethylene in abiotic stress tolerance. Trends in plant science 20(4): 219-229. DOI 10.1016/j.tplants.2015.02.001.

Krishnamurthy P, Mohanty B, Wijaya E, Lee DY, Lim TM, Lin Q, Xu J, Loh CS, Kumar PP. 2017. Transcriptomics analysis of salt stress tolerance in the roots of the mangrove Avicennia officinalis. Scientific reports 7(1): 10031 DOI 10.1038/s41598-017-10730-2. 
567 Kumar RR, Goswami S, Sharma SK, Kala YK, Rai GK, Mishra DC, Grover M, Singh GP, Pathak 568 H, Rai A, Chinnusamy V, Rai RD. 2015. Harnessing next generation sequencing in climate 569 change: RNA-Seq analysis of heat stress-responsive genes in wheat (Triticum aestivum L.). $570 \quad$ OMICS 19(10): 632-47 DOI 10.1089/omi.2015.0097.

571 Lai CP, Huang LM, Chen LF, Chan MT, Shaw JF. 2017. Genome-wide analysis of GDSL-type 572 esterases/lipases in Arabidopsis. Plant molecular biology 95(1-2): 181-197 DOI $573 \quad 10.1007 / \mathrm{s} 11103-017-0648-y$.

574 Lee BH, Henderson DA, Zhu JK. 2005. The Arabidopsis cold-responsive transcriptome and its 575 regulation by ICE1. The Plant cell 17(11): 3155-3175 DOI 10.1105/tpc.105.035568.

576 Li B, Dewey CN. 2011. RSEM: accurate transcript quantification from RNA-Seq data with or 577 without a reference genome. BMC Bioinformatics 4(12): 323 DOI 10.1186/1471-2105-12-

Li R, Li Y, Kristiansen K, Wang J. 2008. SOAP: short oligonucleotide alignment program. 580 Bioinformatics 24(5): 713-714 DOI 10.1093/bioinformatics/btn025.

581

582

583

584

585

586

587

588

589

590

591

592

593

Li Y, Wang X, Ban Q, Zhu X, Jiang C, Wei, C, Bennetzen JL. 2019. Comparative transcriptomic analysis reveals gene expression associated with cold adaptation in the tea plant Camellia sinensis. BMC genomics 20(1): 624. DOI 10.1186/s12864-019-5988-3.

Lippold F, Sanchez DH, MusialakM, Schlereth A, Scheible WR, Hincha DK, Udvardi MK. 2009 AtMyb41 regulates transcriptional and metabolic responses to osmotic stress in Arabidopsis. Plant physiology 149(4): 1761-1772. DOI 10.1104/pp.108.134874

Livak KJ and Schmittgen TD. 2001. Analysis of relative gene expression data using real-time

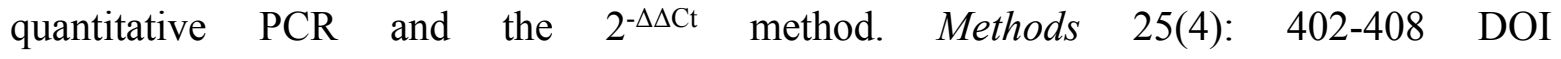
10.1006/meth.2001.1262.

Ma YY, Zhang YL, Lu J, Shao HB. 2009. Roles of plant soluble sugars and their responses to plant cold stress. African Journal of Biotechnology 8:2004-2010 DOI 10.1186/1471-216410-234.

Marè C, Mazzucotelli E, Crosatti C, Francia E, Stanca AM, \& Cattivelli L. 2004. Hv-WRKY38: 
594

595

596

597

598

599

600

601

602

603

604

605

606

607

608

609

610

611

612

613

614

615

616

617

618

619

620

a new transcription factor involved in cold- and drought-response in barley. Plant molecular biology 55(3): 399-416 DOI 10.1007/s11103-004-0906-7.

Mittler R. 2002. Oxidative stress, antioxidants and stress tolerance. Trends in plant science 7(9): 405-410 DOI 10.1016/s1360-1385(02)02312-9.

Mizoi J, Shinozaki K, Yamaguchi-Shinozaki K. 2012. AP2/ERF family transcription factors in plant abiotic stress responses. Biochim Biophys Acta 1819(2): 86-96 DOI 10.1016/j.bbagrm.2011.08.004.

Mutlu S, Karadaolu A, Nalbantolu B. 2013. Protective role of salicylic acid applied before cold stress on antioxidative system and protein patterns in barley apoplast. Biologia Plantarum 57(3): 507-513 DOI 10.1007/s10535-013-0322-4.

Nakashima K, Ito Y, Yamaguchi-Shinozaki K. 2009. Transcriptional regulatory networks in response to abiotic stresses in Arabidopsis and grasses. Plant physiology 149(1): 88-95 DOI 10.1104/pp.108.129791.

Nemhauser JL, Hong F, Chory J. 2006. Different plant hormones regulate similar processes through largely nonoverlapping transcriptional responses. Cell 126(3): 467-75 DOI 10.1016/j.cell.2006.05.050.

Nievola CC, Carvalho CP, Carvalho V, Rodrigues E. 2017. Rapid responses of plants to temperature changes. Temperature (Austin) 4(4):371-405 DOI 10.1080/23328940.2017.1377812.

Nolan TM, Brennan B, Yang M, Chen J, Zhang M, Li Z, Wang X, Bassham DC, Walley J, Yin, Y. 2017. Selective Autophagy of BES1 Mediated by DSK2 Balances Plant Growth and Survival. Developmental cell, 41(1): 33-46.e7 DOI 10.1016/j.devcel.2017.03.013.

Park MY, Kang JY, Kim SY. 2011. Overexpression of AtMYB52 confers ABA hypersensitivity and drought tolerance. Molecules and cells, 31(5): 447-454 DOI 10.1007/s10059-011-03007.

Peleg Z, Blumwald E. 2011. Hormone balance and abiotic stress tolerance in crop plants. Current opinion in plant biology 14(3): 290-295 DOI 10.1016/j.pbi.2011.02.001 
621 Peng YL, Wang YS, Fei J, Sun CC, Cheng H. 2015. Ecophysiological differences between three

622

623

624

625

626

627

628

629

630

631

632

633

634

635

636

637

638

639

640

641

642

643

644

645

646

647

mangrove seedlings (Kandelia obovata, Aegiceras corniculatum, and Avicennia marina) exposed to chilling stress. Ecotoxicology 24(7-8): 1722-1732 DOI 10.1007/s10646-015$1488-7$.

Pitzschke A, Schikora A, \& Hirt H. 2009. MAPK cascade signalling networks in plant defence. Current opinion in plant biology 12(4): 421-426.

Ren H, Lu HF, Shen WJ, Huang C, Guo QF, Li ZA, Jian SG. 2002. Sonneratia apetala Buch.Ham in the mangrove ecosystems of China: An invasive species or restoration species? Ecological Engineering 35:1243-1248 DOI 10.1016/j.ecoleng.2009.05.008.

Robertsen AI, Alongl DM. 1992. Tropical Mangrove Ecosystem. American Geophysical Union, Washington, DC, 130pp.

Román Á, Andreu V, Hernández ML, Lagunas B, Picorel R, Martínez-Rivas JM, \& Alfonso M. 2012. Contribution of the different omega-3 fatty acid desaturase genes to the cold response in soybean. Journal of experimental botany, 63(13): 4973-4982 DOI 10.1093/jxb/ers 174

Rutten D, Santarius KA, 1992. Relationship between frost tolerance and sugar concentration of various bryophytes in summer and winter. Oecologia 91:260-265.

Sah SK, Reddy KR, Li J. 2016. Abscisic Acid and Abiotic Stress Tolerance in Crop Plants. Frontiers in plant science 7: 571. DOI 10.3389/fpls.2016.00571

Schmitt K, Duke NC. 2015. Mangrove Management, Assessment and Monitoring. Tropical Forestry Handbook. Springer Berlin Heidelberg. pp1725-1759 DOI 10.1007/978-3-64241554-8_126-1.

Su W, Ye C, Zhang Y, Hao S, Li QQ. 2019. Identification of putative key genes for coastal environments and cold adaptation in mangrove Kandelia obovata through transcriptome analysis. The Science of the total environment 681: 191-201 DOI 10.1016/j.scitotenv.2019.05.127.

Sun J, Peng X, Fan W, Tang M, Liu J, Shen S. 2014. Functional analysis of BpDREB2 gene involved in salt and drought response from a woody plant Broussonetia papyrifera. Gene 
648

649

650

651

652

653

654

655

656

657

658

659

660

661

662

663

664

665

666

667

668

669

670

671

672

673

674

535(2):140-149 DOI 10.1016/j.gene.2013.11.047.

Sung DY, Kaplan F, Lee KJ, Guy CL. 2003. Acquired tolerance to temperature extremes. Trends in plant science, 8(4): 179-187. DOI 10.1016/S1360-1385(03)00047-5

Suzuki N and Mittler R. 2006. Reactive oxygen species and temperature stresses: a delicate balance between signaling and destruction. Physiologia Plantarum 126(1): 45-51 DOI 10.1111/j.0031-9317.2005.00582.x.

Tähtiharju S, Palva T. 2001. Antisense inhibition of protein phosphatase 2C accelerates cold acclimation in Arabidopsis thaliana. The Plant journal 26(4): 461-470 DOI 10.1046/j.1365313x.2001.01048.x.

Tang M, Liu X, Deng H, Shen S. 2011. Over-expression of JcDREB, a putative AP2/ERF domaincontaining transcription factor gene in woody biodiesel plant Jatropha curcas, enhances salt and freezing tolerance in transgenic Arabidopsis thaliana. Plant science 181(6): 623-31 DOI 10.1016/j.plantsci.2011.06.014.

Theocharis A, Clément C, Barka EA. 2012. Physiological and molecular changes in plants grown at low temperatures. Planta 235(6): 1091-1105 DOI 10.1007/s00425-012-1641-y.

Thomashow MF. 1999. Plant cold acclimation: freezing tolerance genes and regulatory mechanisms. Annual review of plant physiology and plant molecular biology 50: 571-599. DOI 10.1146/annurev.arplant.50.1.571.

Tomlinson PB. 1999. The Botany of Mangroves. Cambridge University Press, New York, pp126. Tong GL, Jang CS, Kim JY, Dong SK, Park JH, Kim DY. 2006. A Myb transcription factor (TaMyb1) from wheat roots is expressed during hypoxia: roles in response to the oxygen concentration in root environment and abiotic stresses. Physiologia Plantarum 129: 275-385 DOI 10.1111/j.1399-3054.2006.00828.x.

Wang BS, Liao BW, Wang YJ, Zan QJ. 2002. Mangrove forest ecosystem and its sustainable development in shengzhen bay. Beijing China: Science Press (in Chinese).

Wang H, Zou Z, Wang S, Gong M. 2013. Global analysis of transcriptome responses and gene expression profiles to cold stress of Jatropha curcas L. PLoS One 8(12): e82817 DOI 
675

676

677

678

679

680

681

682

683

684

685

686

687

688

689

690

691

692

693

694

695

696

697

698

699

700

701

10.1371/journal.pone.0082817.

Wang K, Bai ZY, Liang QY, Liu QL, Zhang L, Pan YZ, Liu GL, Jiang BB, Zhang F, Jia Y. 2018. Transcriptome analysis of chrysanthemum (Dendranthema grandiflorum) in response to low temperature stress. BMC genomics 19(1): 319 DOI 10.1186/s12864-018-4706-x.

Wang K, Zhong M, Wu YH, Bai ZY, Liang QY, Liu QL, Pan YZ, Zhang L, Jiang BB, Jia Y, Liu GL. 2017. Overexpression of a chrysanthemum transcription factor gene DgNAC1 improves the salinity tolerance in chrysanthemum. Plant cell reports 36(4):571-581 DOI 10.1007/s00299-017-2103-6.

Wang Q, Guan Y, Wu Y, Chen H, Chen F, Chu C. 2008. Overexpression of a rice OsDREBIF gene increases salt, drought, and low temperature tolerance in both Arabidopsis and rice. Plant molecular biology 67(6): 589-602 DOI 10.1007/s11103-008-9340-6.

Wang WQ and Wang M. 2007. The mangrove of China. Science Press, Beijing, China.

Wasternack C, Song S 2017 Jasmonates: biosynthesis, metabolism, and signaling by proteins activating and repressing transcription. Journal of experimental botany 68(6): 1303-1321 DOI 10.1093/jxb/erw443.

Wasternack C, Strnad M. 2018. Jasmonates: News on occurrence, biosynthesis, metabolism and action of an ancient group of signaling compounds. International journal of molecular sciences 19(9): 2539 DOI 10.3390/ijms19092539.

Welling A, Palva ET. 2006. Molecular control of cold acclimation in trees. Physiologia Plantarum 127(2): 167-181 DOI: 10.1111/j.1399-3054.2006.00672.x

Winter H and Huber, SC. 2000. Regulation of sucrose metabolism in higher plants: localization and regulation of activity of key enzymes. Critical reviews in biochemistry and molecular biology 35(4): 253-289 DOI 10.1080/10409230008984165.

Wise RR, Naylor AW. 1987. Chilling-enhanced photooxidation: The peroxidative destruction of lipids during chilling injury to photosynthesis and ultrastructure. Plant physiology 83(2): 272277 DOI10.1104/pp.83.2.272.

Xie G, Kato H, Sasaki K, \& Imai R 2009. A cold-induced thioredoxin h of rice, OsTrx23, 
702

703

704

705

706

707

708

709

710

711

712

713

714

715

716

717

718

719

720

721

722

723

724

725

726

727

728

negatively regulates kinase activities of $O S M P K 3$ and $O S M P K 6$ in vitro. FEBS letters 583(17): 2734-2738. DOI 10.1016/j.febslet.2009.07.057

Xie ZY, Zhou ZL, Li HM, Yu JJ, Jiang JJ, Tang ZH, Ma DF, Zhang BH, Han YH, Li ZY. 2018. High throughput sequencing identifies chilling responsive genes in sweetpotato (Ipomoea $\begin{array}{lllll}\text { batatas Lam.) during } \quad \text { storage. } & \text { Genomics } & \text { 111(5): }\end{array}$ DOI10.1016/j.ygeno.2018.05.014.

Yamanaka T, Miyama M, Tada Y. 2009. Transcriptome profiling of the mangrove plant Bruguiera gymnorhiza and identification of salt tolerance genes by Agrobacterium functional screening. Bioscience, biotechnology, and biochemistry 73(2): 304-310 DOI 10.1271/bbb.80513.

Yang T, Huang XS. 2018. Deep sequencing-based characterization of transcriptome of Pyrus ussuriensis in response to cold stress. Gene 661:109-118 DOI10.1016/j.gene.2018.03.067.

Yang X, Zhao T, Rao P, Gao K, An X. 2019. Transcriptome profiling of Populus tomentosa under cold stress. Industrial Crops and Products 135:283-293 DOI10.1016/j.indcrop.2019.04.056.

Yang Y, Yang S, Li J, Deng Y, Zhang Z, Xu S, Guo W, Zhong C, Zhou R, Shi S. 2015a Transcriptome analysis of the Holly mangrove Acanthus ilicifolius and its terrestrial relative, Acanthus leucostachyus, provides insights into adaptation to intertidal zones. BMC Genomics 16(1): 605 DOI10.1186/s12864-015-1813-9.

Yang Y, Yang S, Li J, Li X, Zhong C, Huang Y, Zhou R, Shi S. 2015b. De novo assembly of the transcriptomes of two yellow mangroves, Ceriops tagal and C. zippeliana, and one of their terrestrial relatives, Pellacalyx yunnanensis. Mar Genomics 23:33-6 DOI10.1016/j.margen.2015.04.003.

Yao YX, Dong QL, Zhai H, You CX, Hao YJ. 2011. The functions of an apple cytosolic malate dehydrogenase gene in growth and tolerance to cold and salt stresses. Plant physiology and biochemistry 49(3): 257-64 DOI10.1016/j.plaphy.2010.12.009.

Ye YJ, Xiao YY, Han YC, Shan W, Fan ZQ, Xu QG, Kuang JF, Lu WJ, Lakshmanan P, \& Chen JY. 2016. Banana fruit VQ motif-containing protein5 represses cold-responsive transcription factor MaWRKY26 involved in the regulation of JA biosynthetic genes. Scientific reports 6: 
23632. DOI $10.1038 /$ srep 23632

Young MD, Wakefield MJ, Smyth GK, Oshlack A. 2010. Gene ontology analysis for RNA-seq: accounting for selection bias. Genome biology 11(2): R14 DOI10.1186/gb-2010-11-2-r14.

Zan QJ, Wang BS, Wang YJ, Li MG. 2003. Ecological assessment on the introduced Sonneratia caseolaris and Sonneratia apetala at the mangrove forest of Shenzhen Bay, China. Acta Botanica Sinica 45:544-555.

Zhang X, Fowler SG, Cheng H, Lou Y, Rhee, SY, Stockinger EJ, \& Thomashow MF. 2004. Freezing-sensitive tomato has a functional $\mathrm{CBF}$ cold response pathway, but a CBF regulon that differs from that of freezing-tolerant Arabidopsis. Plant journal, 39(6): 905-919 DOI 10.1111/j.1365-313X.2004.02176.x.

Zhang Y, Yu H, Yang X, Li Q, Ling J, Wang H, Gu X, Huang S, Jiang W. 2016. CsWRKY46, a WRKY transcription factor from cucumber, confers cold resistance in transgenic-plant by regulating a set of cold-stress responsive genes in an ABA-dependent manner. Plant physiology and biochemistry 108: 478-487 DOI10.1016/j.plaphy.2016.08.013.

Zhao L, Nicholson JK, Lu A, Wang Z, Tang H, Holmes E, Shen J, Zhang X, Li JV, Lindon JC. 2012. Targeting the human genome-microbiome axis for drug discovery: inspirations from global systems biology and traditional Chinese medicine. Journal of proteome research 11(7): 3509-3519 DOI10.1021/pr3001628.

Zhou MQ, Shen C, Wu LH, Tang KX, Lin J. 2011. CBF-dependent signaling pathway: a key responder to low temperature stress in plants. Critical reviews in biotechnology. 31(2): 186192 DOI10.3109/07388551.2010.505910.

Zou C, Jiang W, Yu D. 2010. Male gametophyte-specific WRKY34 transcription factor mediates cold sensitivity of mature pollen in Arabidopsis. Journal of experimental botany 61(14): 3901-3914 DOI10.1093/jxb/erq204. 
Figure 1

Phenotypic changes of $S$. caseolaris under chilling stress $\left(4^{\circ} \mathrm{C}\right)$.

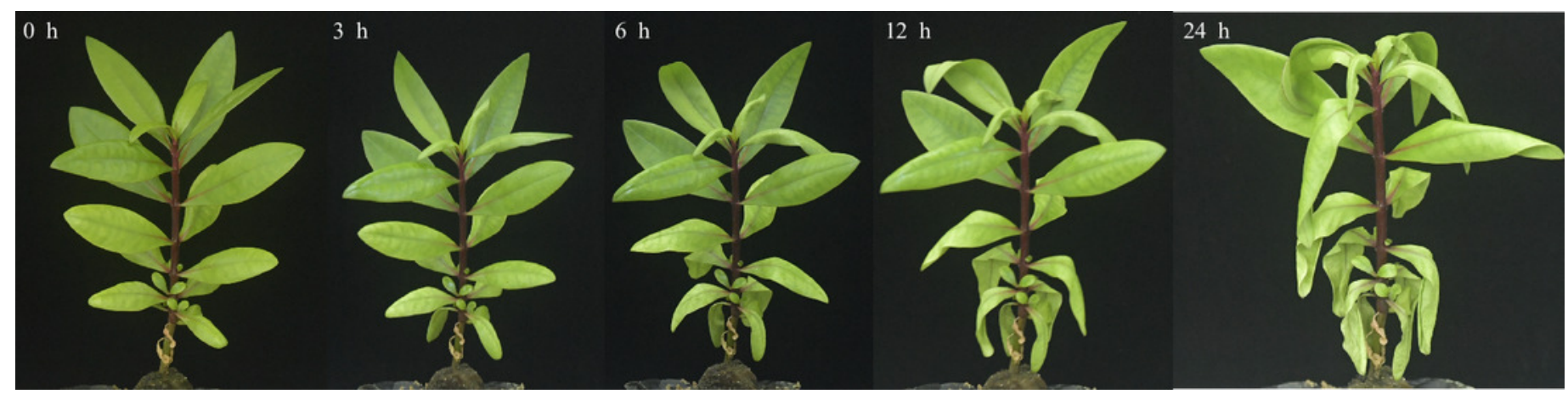


Figure 2

Physiological change of $S$. caseolaris in chilling stress. Error bar indicates \pm SD of three replicates.

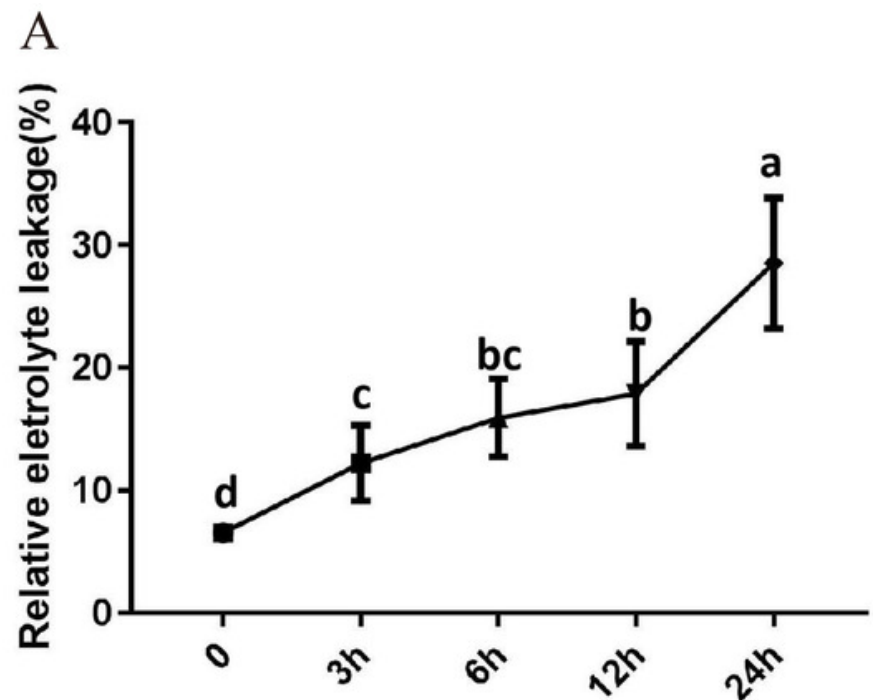

C

Time

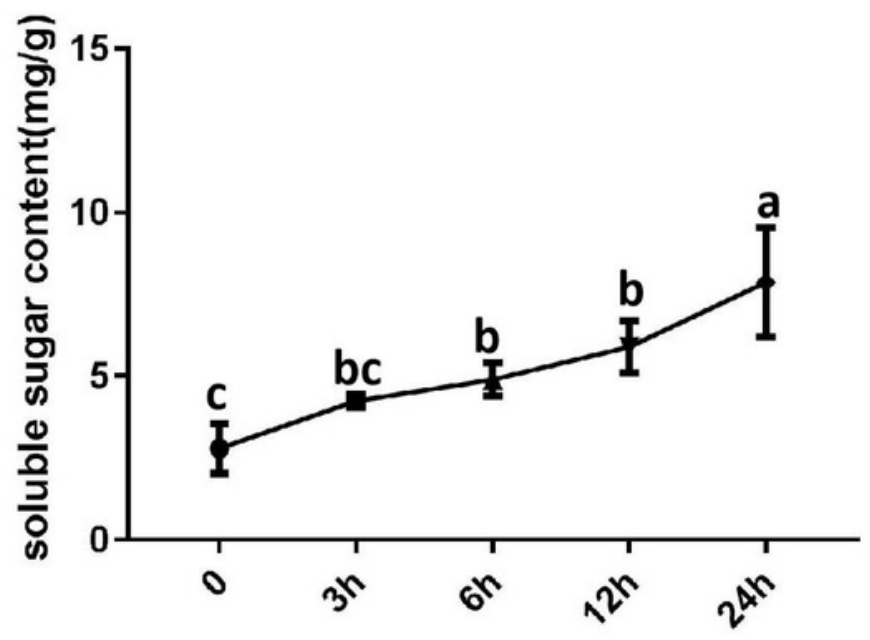

Time
B

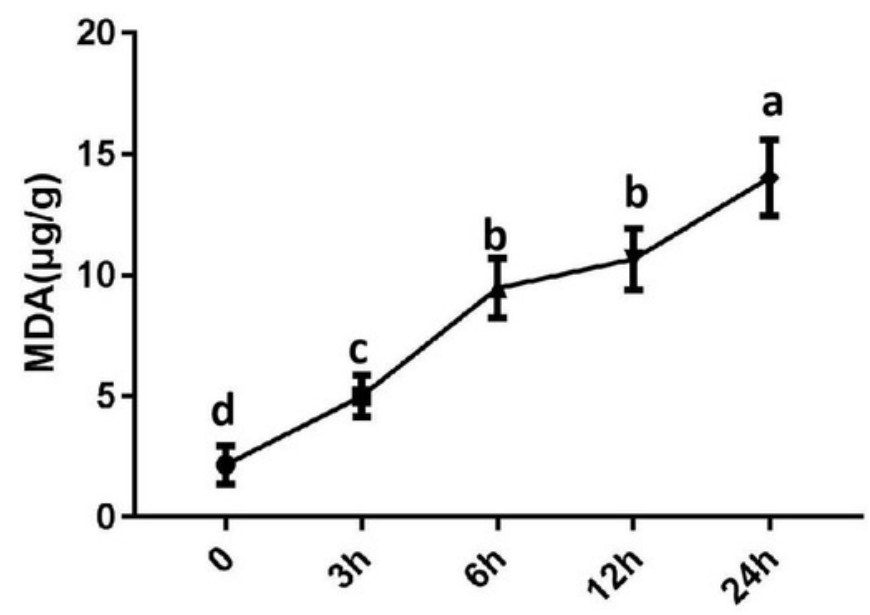

Time

D

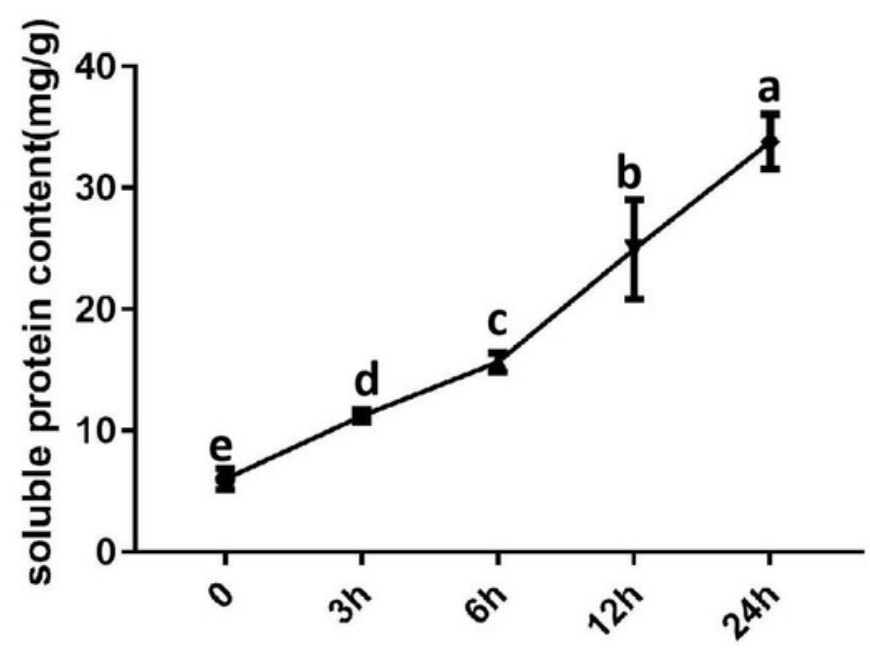

Time 
Figure 3

The top $20 \mathrm{GO}$ and KEGG enrichment scatter diagram depicting the differential expression of genes. A: the top $20 \mathrm{GO}$ enrichment. B: KEGG enrichment.

A

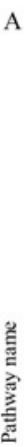

translation initiation factor activity

transcription, DNA-templated

starch binding

sequence-specific DNA bindim

regulation of

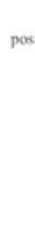
positive regs
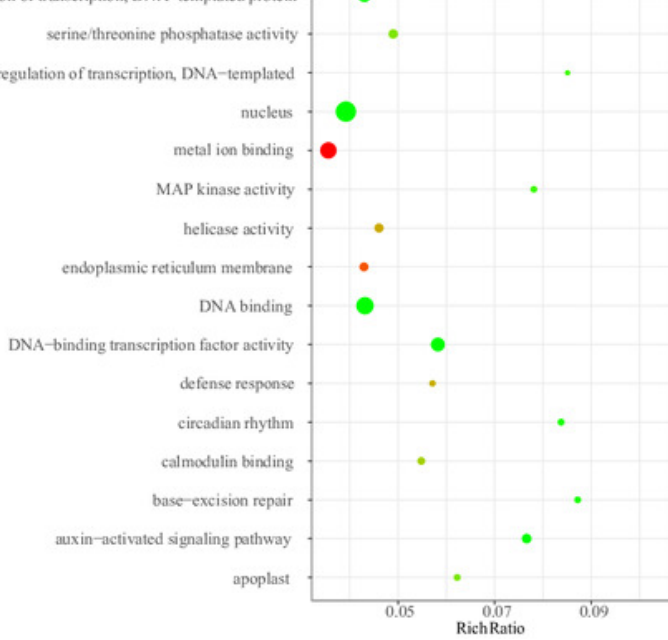

B

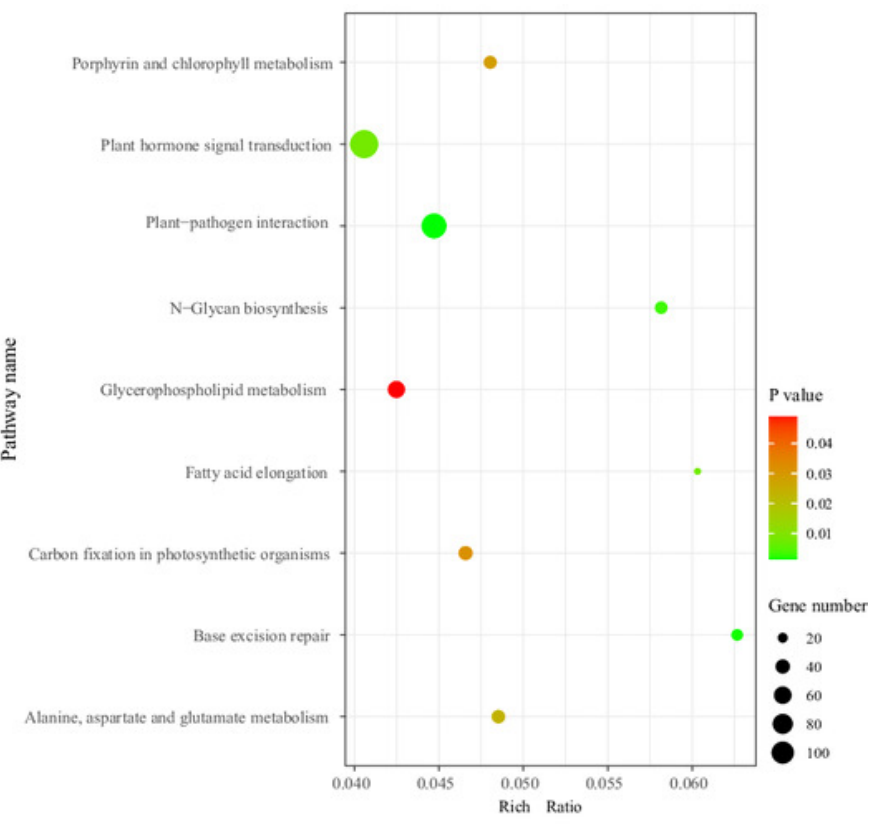


Figure 4

Figure 4 Heat map of relative expression levels of DEGs involved in main transcription factors, sugar metabolism and the antioxidant defense system. A: The main sugar metabolism-related genes. B: The main antioxidant-related genes. C: The main transcripti 


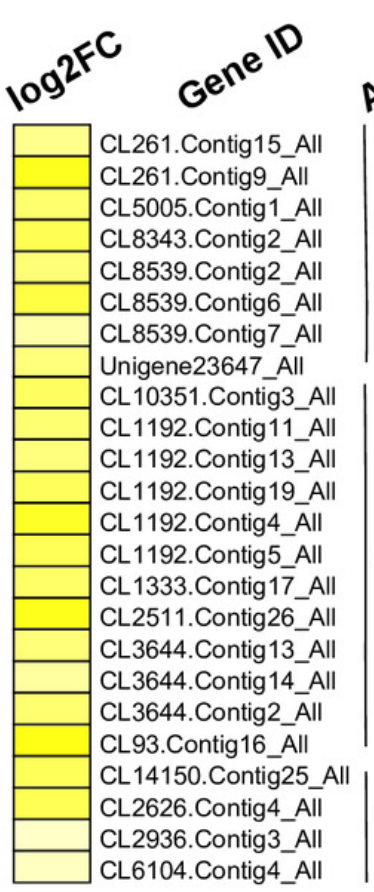

sucrose

CL10181.Contig4_All CL10181.Contig5_All CL10181.Contig8_All CL10611.Contig4_All CL12294.Contig2_All CL14121.Contig7_All CL2179.Contig2_All CL2179.Contig5_All CL3440.Contig1_All CL3775.Contig1_All CL3775.Contig3_All CL4770.Contig2_All CL6322.Contig1_All CL6322.Contig3_All CL6507.Contig1_All CL7927.Contig1_All CL8409.Contig2_All CL934.Contig12_All CL9944.Contig1_All CL9944.Contig2_All Unigene1116_All Unigene12005_All Unigene1243_All Unigene14290_All Unigene14824_All Unigene21323_All Unigene21412_All Unigene27787_All Unigene27797_All Unigene7038_All CL14010.Contig25_All CL14010.Contig9_All CL1776.Contig14_All CL3433.Contig13_All CL3433.Contig15_All CL3433.Contig22_All CL3433.Contig6_All CL3433.Contig8_All CL3433.Contig9_All CL512.Contig48_All CL8248.Contig1_All CL8248.Contig4_All Unigene10651_All

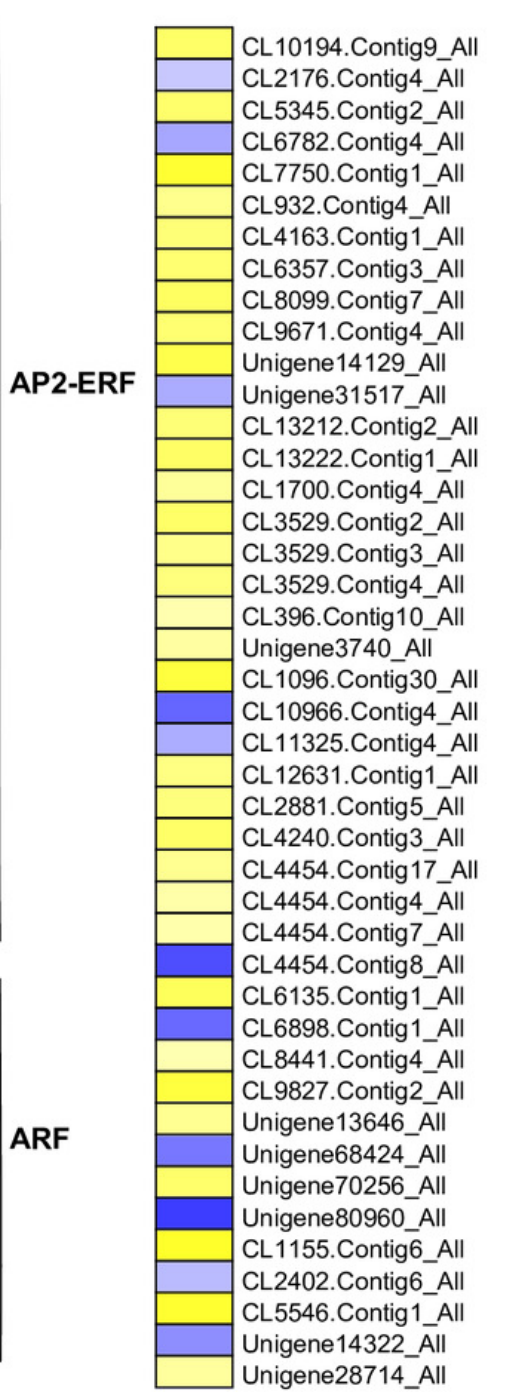

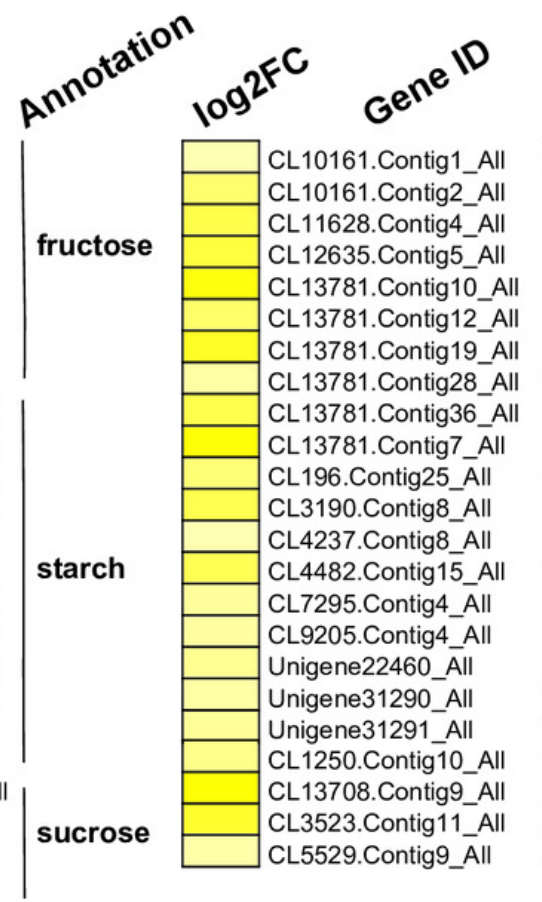
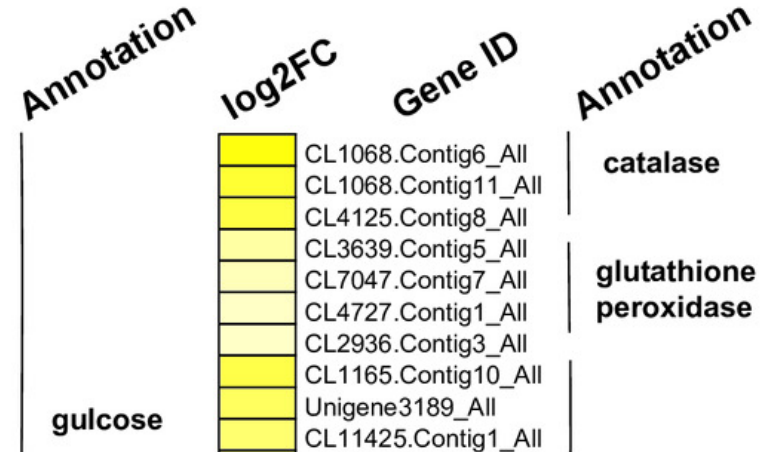

trehalose

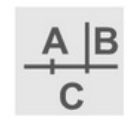

$\begin{array}{lllllll}-9.00 & -6.00 & -3.00 & 0.00 & 3.00 & 6.00 & 9.00\end{array}$

bHLH

C2C2-GATA CL2936.Contig3 All CL1165.Contig10_All Unigene3189_All CL11425.Contig1_All CL10965.Contig3_All Unigene30085_All Unigene 5748_All CL3639.Contig6_All CL355.Contig5_All Unigene30041_All CL13638.Contig5_All CL1068.Contig7_All Unigene30063_All

peroxidase

superoxide dismutase
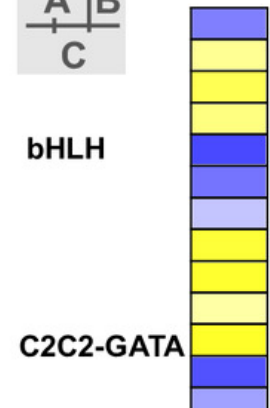

CL11254.Contig2_All CL11563.Contig2 All CL1244.Contig1_All CL13302.Contig2 All CL1346.Contig2_All CL1346.Contig5_All CL13666.Contig3_All CL1853.Contig21_All CL614.Contig18_All CL6673.Contig9_All CL720.Contig1_All CL727.Contig4_All Unigene18145_All Unigene28974_All Unigene29122_All CL1225.Contig17_All CL1225.Contig3 All CL3253.Contig12_All CL448.Contig25 All CL448.Contig9_All Unigene10677_All Unigene10679_All Unigene17225_All Unigene2838_All Unigene3992_All CL10252.Contig3_All CL10252.Contig6_All CL1282.Contig10 All CL1282.Contig6_All CL1282.Contig8 All CL14176.Contig2_All CL14176.Contig4_All CL1629.Contig9_All CL2062.Contig1_All CL2154.Contig1_All CL2154.Contig6_All CL2285.Contig4_All CL3984.Contig7_All CL4527.Contig3_All CL649.Contig6_All CL652.Contig14 All CL7364.Contig2_All CL7364.Contig4 All CL8390.Contig3_All CL9685.Contig3_All
MYB

SBP

WRKY 
Figure 5

Figure 5 Plant hormone signal transduction and the relative heat map. A Plant hormone signal transduction. B Heat map of DEGs involved with auxin, ABA, EN and JA.

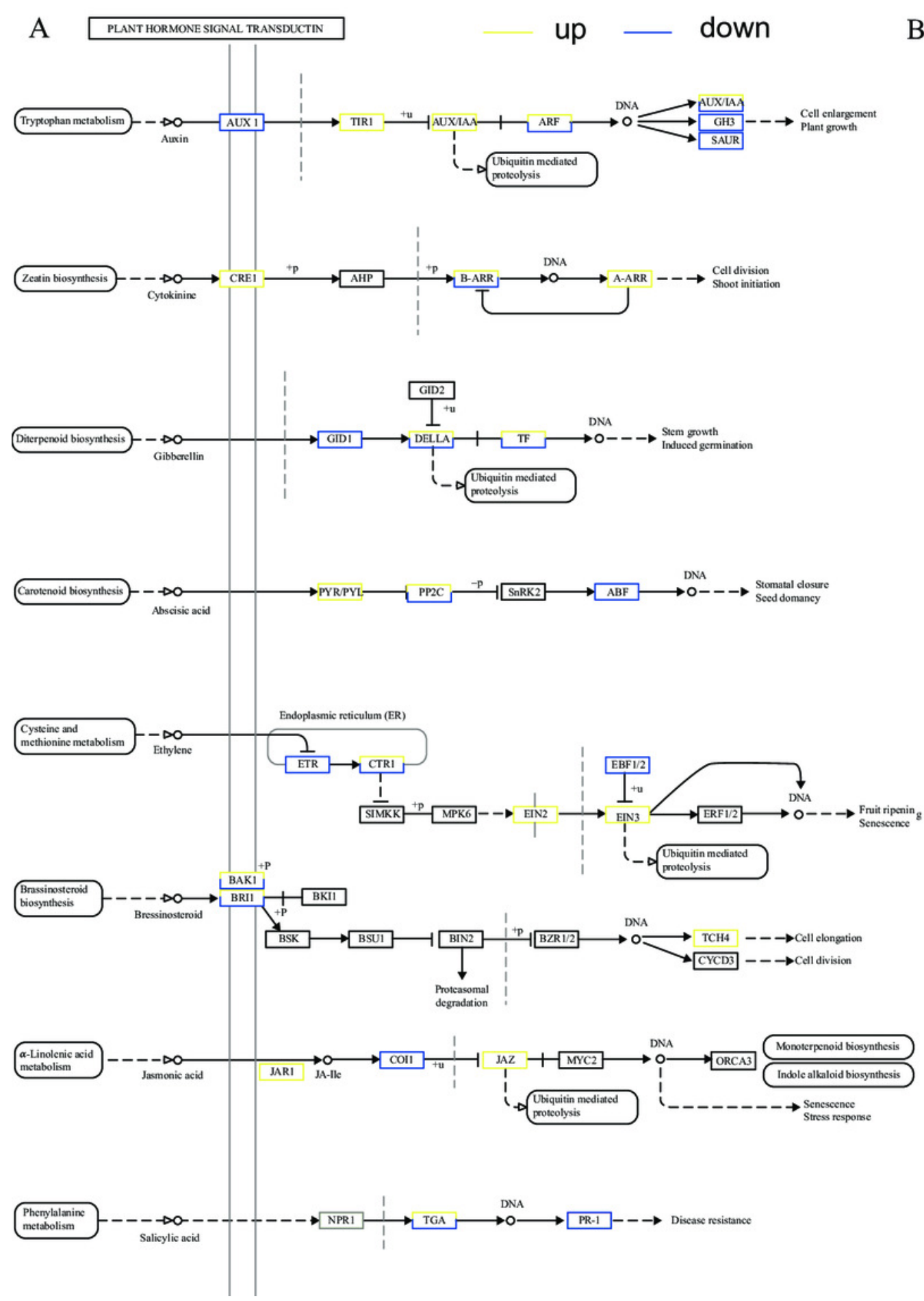

B

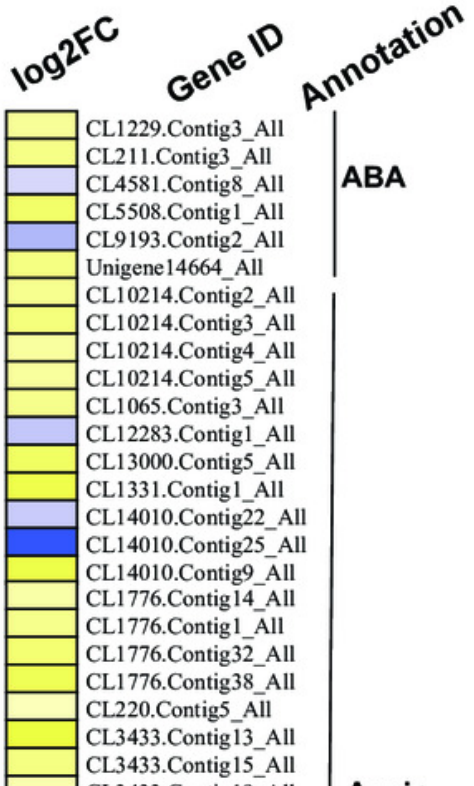

CL3433. Contig

CL3433.Contig22_All CL3433.Contig27_All CL3433.Contig6 All CL3433.Contig8_All CL3433.Contig9_All CL3871.Contig2_All CL4277.Contig7 All CL512.Contig23_All CL512.Contig48_All CL5422.Contig5 All CL59.Contig3_All CL798.Contig23_All CL798.Contig29 Al CL8234.Contig2_All CL8234.Contig5_All CL8234.Contig7_All CL8248.Contig1 Al CL8248.Contig4_All Unigene 10651_All Unigene 13181_Al

Unigene 17861 All

Unigene23758_Al

Unigene27366_All

Unigene 74287 All

CL2232.Contig4_All CL4076.Contig23_All CL4482.Contig15_All CL4482.Contig18 All CL450.Contig23_All CL450.Contig31_All CL4552.Contig7_All CL5592.Contig3_All CL7543.Contig4_All CL10719.Contig2_All CL11723.Contig2 All CL1479.Contig2_Al CL2129.Contig2_All CL2588.Contig7 All CL2588.Contig9_All
Auxin

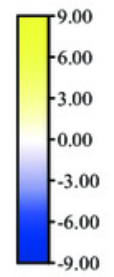

ET 


\section{Figure 6}

Expression of S. caseolaris genes in response to chilling stress for $0 \mathrm{~h}$ (CK) and $6 \mathrm{~h}$ (CT) as determined by qRT-PCR (blue) and RNA-seq (red).
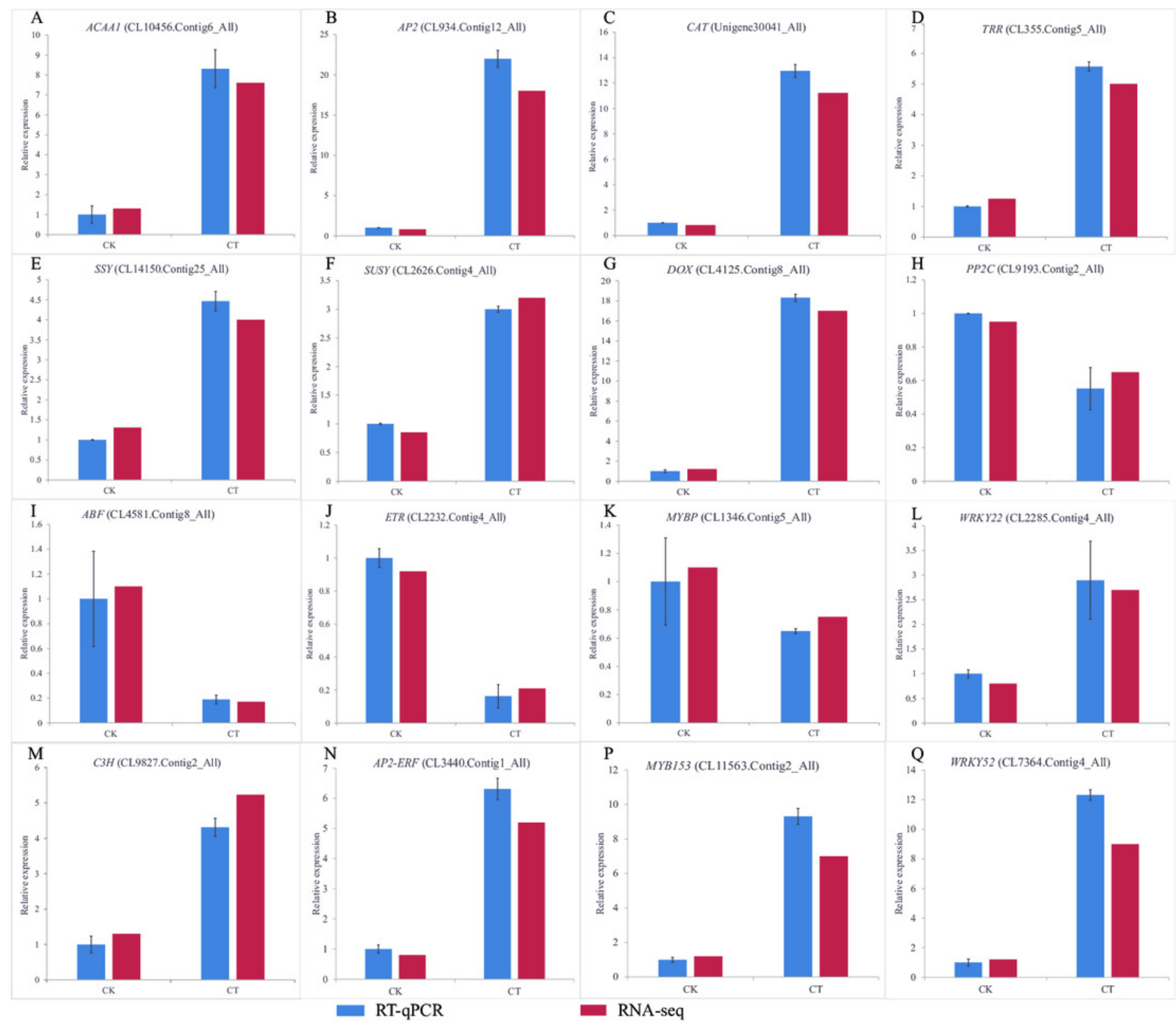
Figure 7

Hypothetical model of the events occurring in the S. caseolaris leaves under chilling stress. 


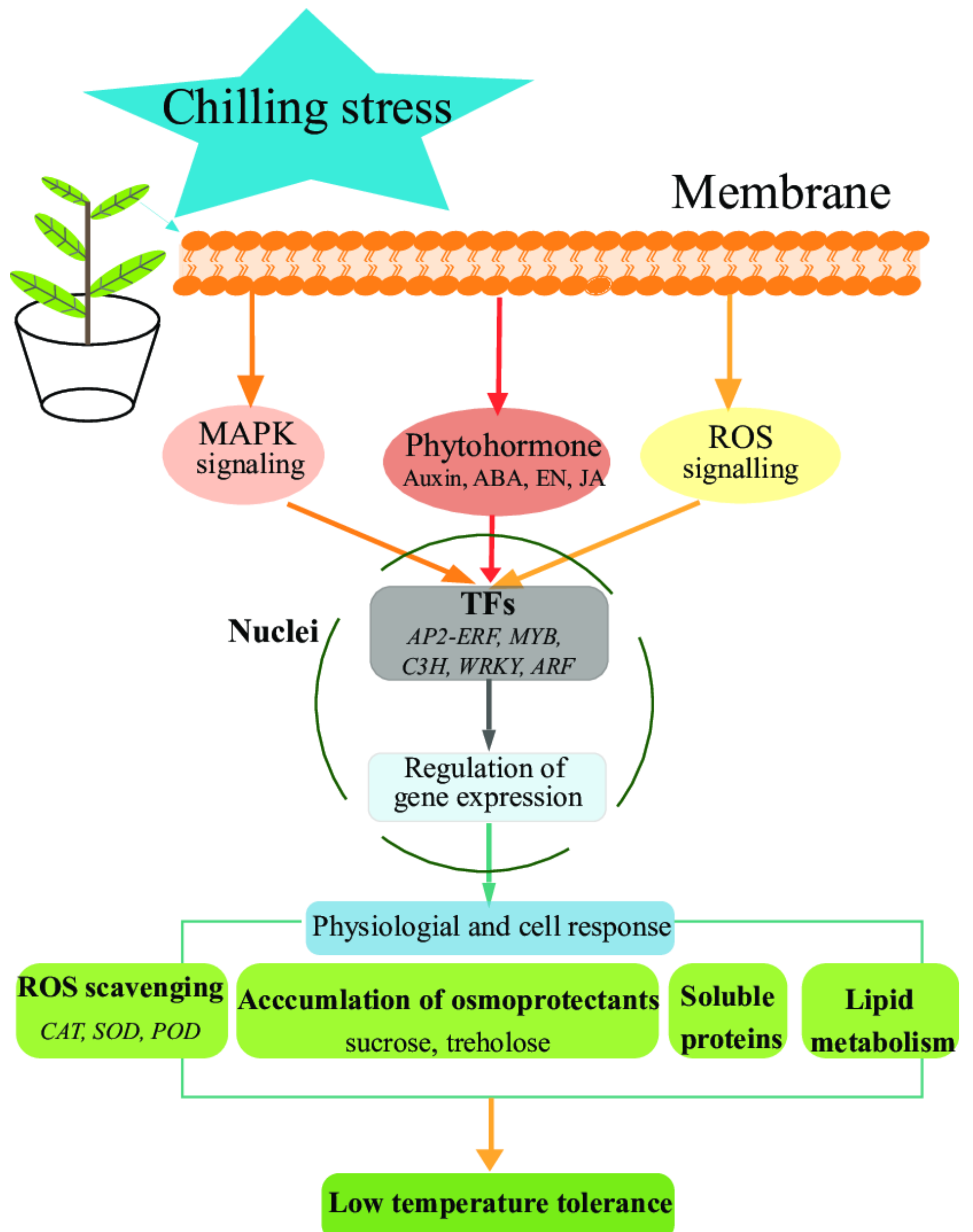

